\title{
Rate-Dependent Cyclic Lateral Load Test on a Single Pile in Sand
}

\author{
Naba Raj Shrestha, Masato Saitoh, Alok Kumer Saha, Chandra Shekhar Goit \\ Saitama University \\ 255 Shimo-Okubo, Sakura-ku, Saitama, Japan
}

shrestha.n.r.322@ms.saitama-u.ac.jp; saity@mail.saitama-u.ac.jp; alokbaec@gmail.com; chandra@mail.saitama-u.ac.jp

\begin{abstract}
The loading rate effect on a single pile subjected cyclic lateral loads is studied experimentally. The scaled model pile embedded in cohesionless sand is housed in a laminar shear box under $1 \mathrm{~g}$ condition. Loads are applied with a horizontal actuator rigidly connected at the pile-head allowing only horizontal translation. The results show the significant effect of loading rate in bearing capacity of the lateral pile subjected to cyclic loading. Further, the variation of the lateral resistance of the pile are found to be linear function of logarithmic of the loading rate. However, no effect of loading rate appears in the bending moment, deflection and soil reaction profile along the pile depth, which indicates that soil near the pile show a consistent failure pattern despite a significant change in the loading velocity.
\end{abstract}

Keywords: single pile, cyclic load test, rate effect, model testing

\section{Introduction}

Single piles in coastal and offshore structures are inevitably subjected to repetitive lateral loads. Wind, waves, blasts, and water pressures may generate such cyclic lateral loads to the pile supported structures. These loads have wide range of amplitudes and velocities at different time events. Generally, all the cyclic loading sequences can be characterized by four parameters: a) the maximum applied load, b) the load variation amplitude, c) the number of cycles, and d) the loading rate. A number of studies have been conducted in the past considering first three parameters for the soil-pile system subjected to cyclic loading [1]-[4]. However, to the best of authors knowledge, the fourth parameter, i.e., the effect of loading rate on the cyclic lateral loads, has been neglected in most of the experimental investigations as well as analytical and numerical modelling.

In this study, a scaled single pile model embedded in dry homogeneous sand is investigated for lateral cyclic loading with wide range of loading rate and displacement amplitudes. The effect of loading rate on the failure pattern of the soil near the pile during are analysed in terms of load-deflection curve at the pile-head, bending moment distributions, pile deflections profile and soil reaction profile along the pile depth.

\section{Model Test}

Scaling of full-scale prototype to the fit in the laboratory test models are of fundamental importance for the simulation of actual behaviour of soil and structure material under reduced stresses, compared to the prototype. For the present experimental investigation, the scaling law derived by Kokusho and Iwatate [5] incorporating the effect of low confining pressure of soil pertaining to $1 \mathrm{~g}$ condition was used. The similitude law considers the ratio of forces acting on the model and the prototype, suggesting a relationship between the model and prototype as,

$$
\begin{gathered}
\frac{\omega_{m}}{\omega_{p}}=\eta^{-1 / 4} \lambda^{-3 / 4}, \text { and } \\
\frac{\gamma_{m}}{\gamma_{p}}=\eta^{1 / 2} \lambda^{1 / 2}
\end{gathered}
$$

where, $\omega_{m}$ and $\omega_{p}$ are the cyclic loading frequency on the model and corresponding frequency on the prototype respectively, $\gamma_{m}$ and $\gamma_{p}$ are the dynamic strain on the model and corresponding strain on the prototype respectively, $\eta$ is the density scaling ratio of the model to the prototype and $\lambda$ is the geometric scaling ratio of the model to the prototype. 
For the current experiment, $\eta$ was adopted as 0.81 and $\lambda$ was adopted 0.05 . Physical dimensions and properties of the prototype and model used in this study are summarized in Table 1.

\subsection{Experimental Setup}

The experimental setup consists of a laminar shear box which is rigidly bolted with unidirectional shaking table owned by Saitama University, Japan. The base plate size of the shaking table is $1800 \mathrm{~mm} \times 1800 \mathrm{~mm}$ with $\pm 200 \mathrm{~mm}$ maximum stroke. The inside measurements of the shear box are $1200 \mathrm{~mm}$ in loading direction, $800 \mathrm{~mm}$ in perpendicular to the loading direction and $1000 \mathrm{~mm}$ in depth (Figure 1).

\subsection{Sand}

Dry, homogeneous and cohesionless Gifu sand found in Japan was employed in the experiment. The standard properties of the Gifu sand include the specific gravity 2.64 maximum diameter $0.84 \mathrm{~mm}$, coefficient of uniformity 1.59 , maximum and minimum void ratio 1.13 and 0.72 , respectively. The friction angle of the Gifu sand is $40.7^{\circ}$.

The sand was put inside the shear box in seven successive layers and ach layer of sand was compacted with shaking table vibration of amplitude $7 \mathrm{~m} / \mathrm{s} 2$ and frequency $40 \mathrm{~Hz}$ to get the desired density of soil $\left(1.46 \mathrm{Mg} / \mathrm{m}^{3}\right)$. The corresponding void ratio was found to be 0.81 with an estimated relative density of $78 \%$.

Table 1: Prototype to model relation

\begin{tabular}{|l|l|l|l|}
\hline Items & Prototype & Model & Units \\
\hline Length of pile $(L)$ & 18.0 & 0.9 & $\mathrm{~m}$ \\
\hline Diameter of Pile $(d)$ & 0.8 & 0.04 & $\mathrm{~m}$ \\
\hline Density of Pile $\left(\rho_{p}\right)$ & 2.4 & 1.5 & $\mathrm{Mg} / \mathrm{m}^{3}$ \\
\hline Young's modulus of pile $\left(E_{p}\right)$ & 25.0 & 2.8 & $\mathrm{GPa}$ \\
\hline Depth of soil $(H)$ & 20.0 & 1.0 & $\mathrm{~m}$ \\
\hline Density of soil $\left(\rho_{s}\right)$ & 1.8 & 1.46 & $\mathrm{Mg} / \mathrm{m}^{3}$ \\
\hline Shear wave velocity $\left(V_{s}\right)$ & 171.5 & 96.0 & $\mathrm{~m} / \mathrm{s}$ \\
\hline Natural frequency of soil $\left(f_{n}\right)$ & 2.14 & 24.0 & $\mathrm{~Hz}$ \\
\hline
\end{tabular}

\subsection{Pile}

A solid cylindrical pile made of polyoxymethylene homopolymer (POM-H) with a diameter $(d)=40 \mathrm{~mm}$ and length $(L)=900 \mathrm{~mm}$ was used. A solid cubical POM-H pile-head $(125 \mathrm{~mm} \times 125 \mathrm{~mm} \times 125 \mathrm{~mm})$ was rigidly connected with the horizontal actuator providing restraints in movements except in the direction of loading. A vertical gap of $35 \mathrm{~mm}$ between the top surface of sand and pile cap was provided to eliminate the resistance of the pile cap. Figure 1(a) shows experimental setup of the single pile embedded in sand inside the shear box.

\subsection{Pile instrumentation}

19 pairs of strain gauges were applied over the length of the pile, as shown in Figure 1(b), to measure the induced bending strain in the loading direction. Strain gauges at shallow depth were placed at close spacing knowing the bending moments and displacements are confined to the pile depths immediately below the pile-head. The curvature is simply calculated by dividing the bending strain with the radius of the pile. Further, the moment $(M)$ at depth $z$ is calculated by multiplying the curvature with flexural rigidity $\left(E_{p} I_{p}\right)$ of the pile. Finally, double differentiation and integration of the bending moment, as shown in Eqs. (3) - (4), provides an indirect estimate of soil resistance, $p$, and the lateral deflection of the pile, $y$, respectively;

$$
p=\frac{d^{2}}{d z^{2}} M
$$




$$
\mathrm{y}=\iint \frac{M}{E_{p} I_{p}} d z d z
$$

Since the bending moment obtained from the experiment was a discrete data set, a continuous smooth data set was obtained from a data fitting. Various solutions for the data fitting and processing for a laterally loaded pile are available in in the literatures such as [5] and [6]. In this experiment, a polynomial equation method was used to process the experimentally experimentally measured bending strain data.

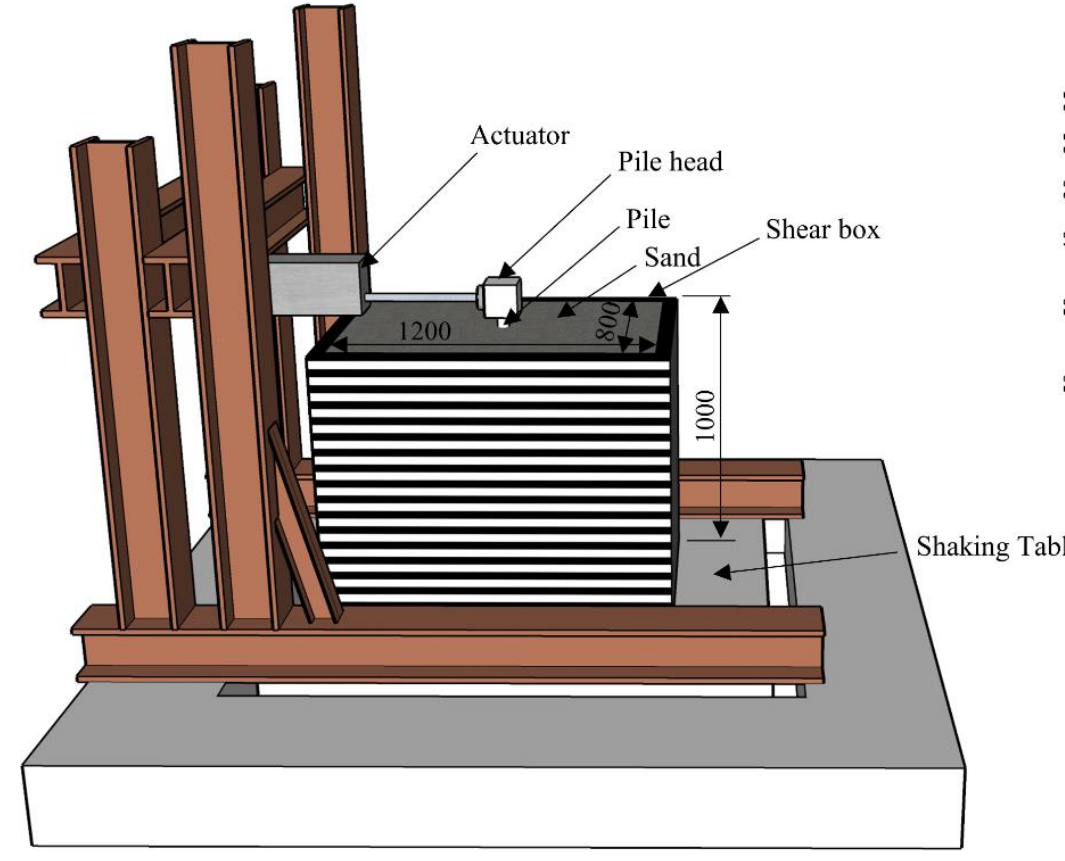

a)

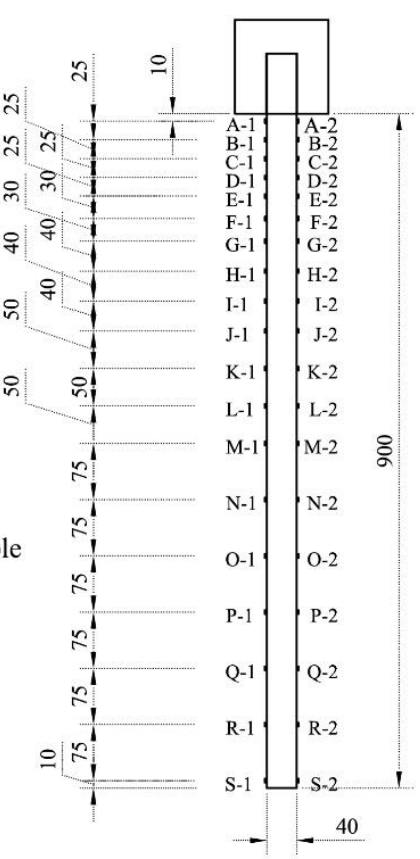

b)

Fig. 1: Experimental setup detail (dimensions in $\mathrm{mm}$ ): a) schematic diagram and b) strain gauge layout

\subsection{Loadings}

The loadings were applied at the pile-head using a digitally controlled unidirectional hydraulic actuator $( \pm 10 \mathrm{kN}, \pm 150$ $\mathrm{mm})$. Four different displacement amplitudes of $5 \%$ of d $(2 \mathrm{~mm}), 10 \%$ of d (4 mm), $15 \%$ of d (6 mm), and $20 \% \mathrm{of} \mathrm{d}(8 \mathrm{~mm})$ with three different loading rates of $0.01 \mathrm{~mm} / \mathrm{s}, 10 \mathrm{~mm} / \mathrm{s}$ and $250 \mathrm{~mm} / \mathrm{s}$ were applied for consecutive 3 cycles. The soil was brought back to initial state after completing one loading rate case with all the displacement amplitude. The loading was applied in the ascending order of the loading amplitude for a selected loading rate case.

\section{Results and Discussion}

The force and pile-head deflection measured from the cyclic loading tests are shown in. Figure 2. The residual displacement in the force-displacement curve reveals the inelastic behaviour of the soil. However, the load deflection curve in the Figure do not show any yielding behaviour even with the large lateral deflection amplitude (20\% of the pile diameter i.e., $8 \mathrm{~mm}$ ). Similar results were reported in the monotonic lateral loading test on single pile by [8]. Degradation in the force in the successive cycles are clear in the loading part of the curve, whereas, unloading part is unaffected by the number of cycles.

Comparing the force-displacement diagrams in Figure 2. (a), Figure 2. (b) and Figure 2. (c) for $0.01 \mathrm{~mm} / \mathrm{s}, 10 \mathrm{~mm} / \mathrm{s}$ and $250 \mathrm{~mm} / \mathrm{s}$, respectively, the force increases with loading rate at any given displacements for both positive and negative cycles 
of the loading. For example, at $8 \mathrm{~mm}$ displacement in the positive cycle, the increase in force with respect to $0.01 \mathrm{~mm} / \mathrm{s}$ loading rate are $11 \%$ and $14 \%$ for $10 \mathrm{~mm} / \mathrm{s}$ and $250 \mathrm{~mm} / \mathrm{s}$ loading rate, respectively.

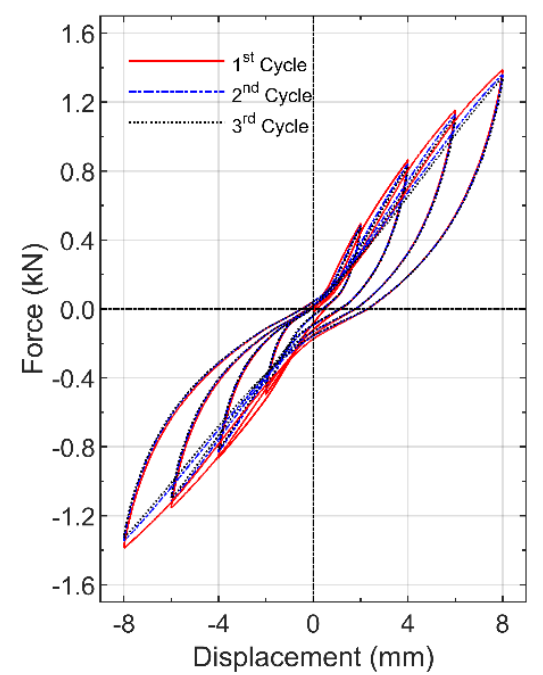

a)

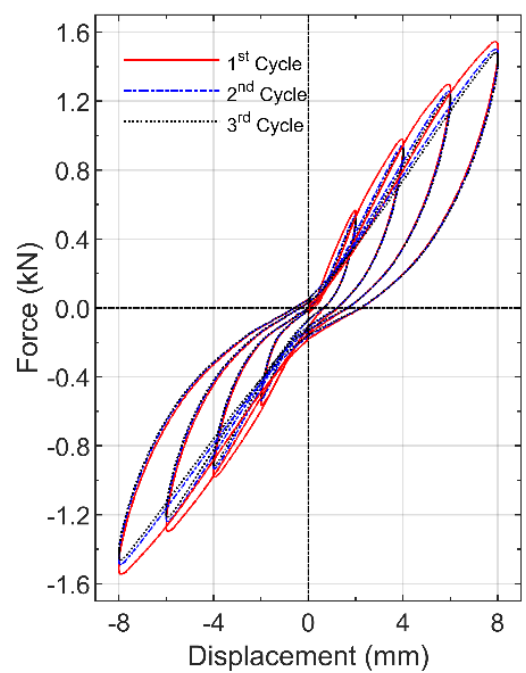

b)

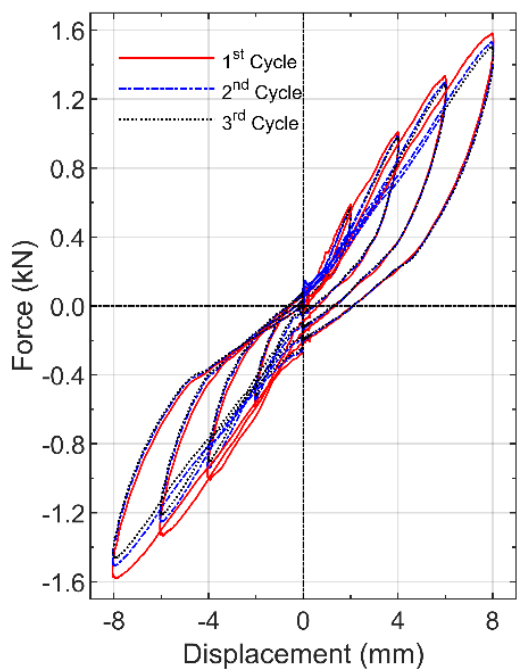

c)

Fig. 2: Force-displacement relationship for: a) $0.01 \mathrm{~mm} / \mathrm{s}$, b) $10 \mathrm{~mm} / \mathrm{s}$ and c) $250 \mathrm{~mm} / \mathrm{s}$

A linear relationship between the force and loading rate is found as illustrated in Figure 3. This proves that the lateral resistance is approximately linearly proportional to the logarithmic of roading rate. The assumption was first proposed by [9] and used by other researches such as [10]. The equation of the fitted straight line in Figure 3 can be written as

$$
F(v)=F\left(v_{r}\right)\left[1-\alpha \log \left(\frac{v_{r}}{v}\right)\right]
$$

Where, $F(v)$ and $F\left(v_{r}\right)$ are the lateral resistance at a specific horizontal deflection at loading rates $v$ and $v_{r}$, respectively; $\alpha$ is a coefficient defined as the increase in lateral resistance normalized by the lateral resistance at the reference loading rate. The $\alpha$ values for the positive cycle of loadings are summarized in Table 2.
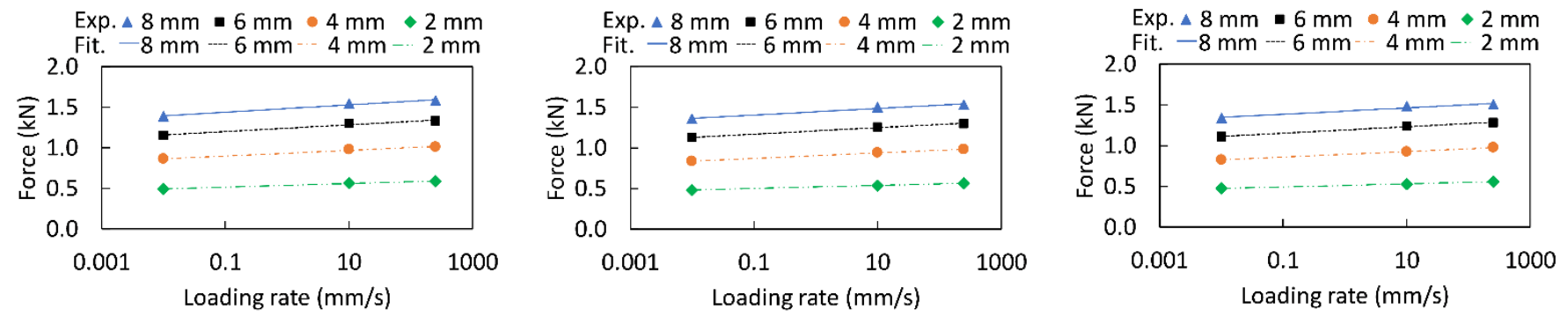

Fig. 3: Force and loading rate in the positive cycle of loading for: a) $1^{\text {st }}$ cycle, b) $2^{\text {nd }}$ cycle and c) $3^{\text {rd }}$ cycle 
Table 2: Values of $\alpha$ at different displacement and different cycle

\begin{tabular}{|l|l|l|l|l|}
\hline Displacements & $2 \mathrm{~mm}$ & $4 \mathrm{~mm}$ & $6 \mathrm{~mm}$ & $8 \mathrm{~mm}$ \\
\hline $1^{\text {st }}$ cycle & 0.040 & 0.037 & 0.034 & 0.031 \\
\hline $2^{\text {nd }}$ cycle & 0.038 & 0.036 & 0.032 & 0.028 \\
\hline $3^{\text {rd }}$ cycle & 0.037 & 0.038 & 0.033 & 0.027 \\
\hline
\end{tabular}

Moreover, bending moment profile along the pile length at various displacements $( \pm 2 \mathrm{~mm}, \pm 4 \mathrm{~mm}, \pm 6 \mathrm{~mm}$ and $\pm 8 \mathrm{~mm})$ with loading rate of $0.01 \mathrm{~mm} / \mathrm{s}, 10 \mathrm{~mm} / \mathrm{s}$, and $250 \mathrm{~mm} / \mathrm{s}$ are presented in Figure 4 (a), Figure 5 (a), and Figure 6(a), respectively, for successive 3 cycles. Out of 19 pairs of strain gauges, 3 pairs were damaged during the experiment, and therefore the data from remaining 16 pairs of strain gauges were utilized. Experimentally evaluated bending moments were fitted with a seven-degree polynomial equation. The fitted equation was further processed with double integration and double differentiation, as described earlier. The two boundary conditions employed during integrations are; a) known displacement at the pile-head, and b) an assumption of zero-degree rotation angle at the pile toe.

In contrast the to the rate dependency on the force-displacement behaviour, the bending moment, displacement and soil reaction profile are similar for different loading rates. This suggests the failure pattern of soil near the pile soil are consistent regardless of the rate of cyclic loading. Moreover, there is no effect of number of cycles on the bending moment, displacement and soil reaction profile of the soil-pile system.

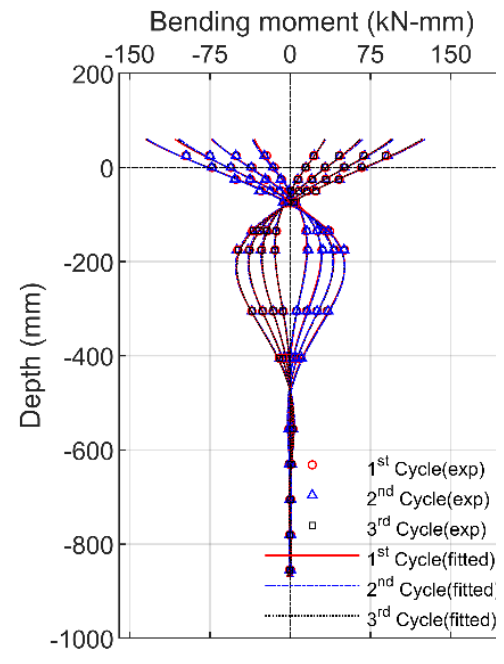

a)

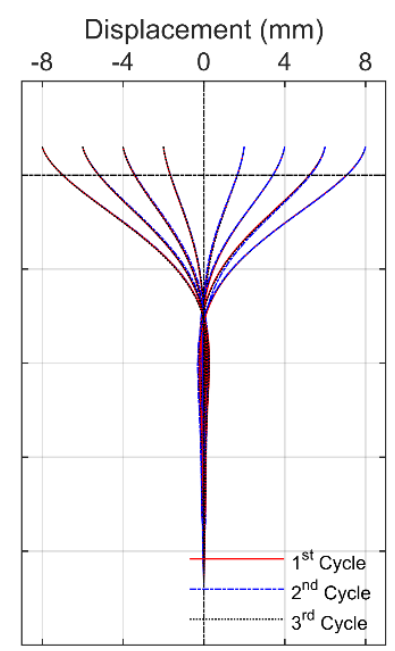

b)

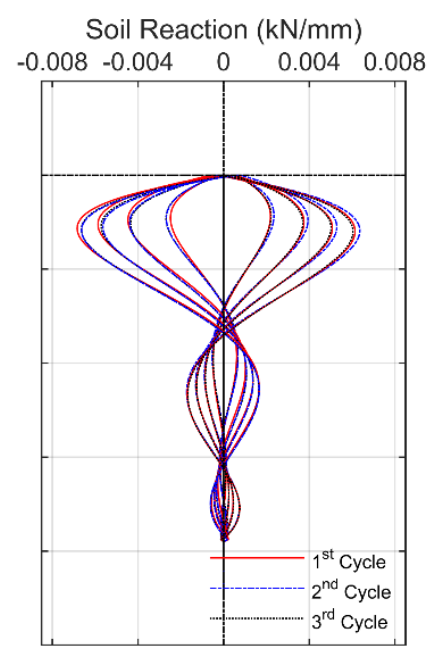

c)

Fig. 4: a) Bending moment, b) lateral deflection and c) soil reaction profile for $0.01 \mathrm{~mm} / \mathrm{s}$ loading 


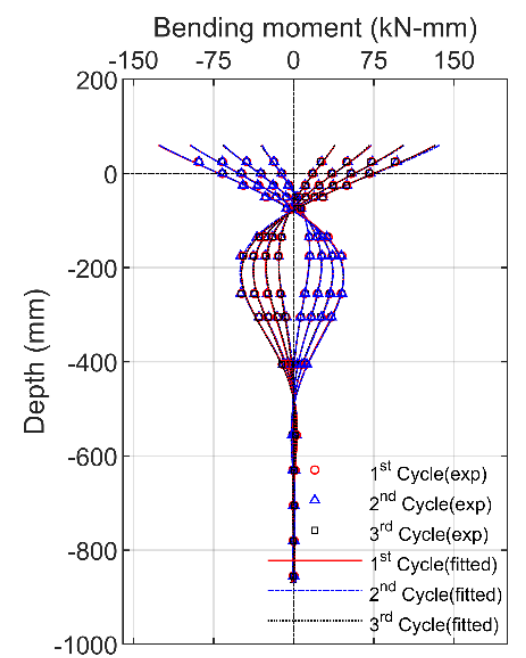

a)

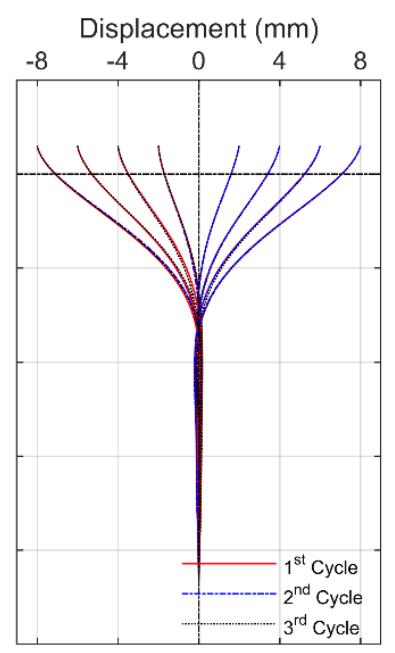

b)

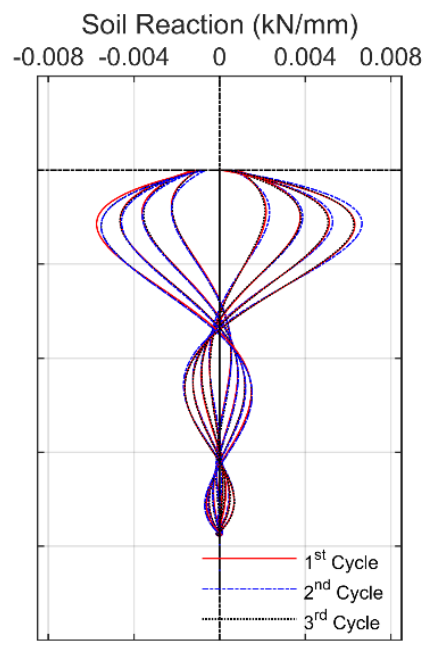

c)

Fig. 5: a) Bending moment, b) lateral deflection and c) soil reaction profile for $10 \mathrm{~mm} / \mathrm{s}$ loading

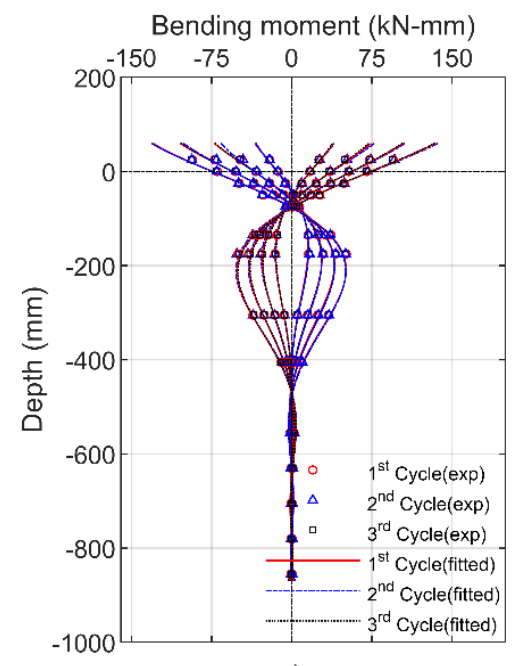

a)

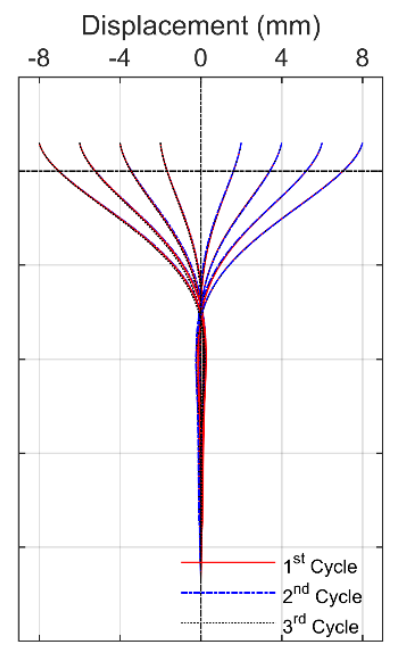

b)

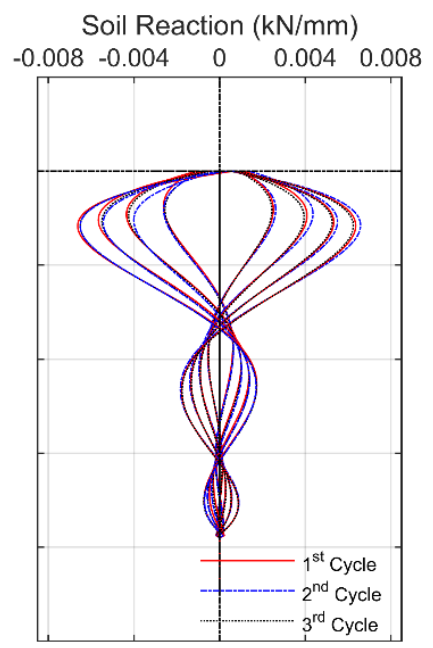

c)

Fig. 6: a) Bending moment, b) lateral deflection and c) soil reaction profile for $250 \mathrm{~mm} / \mathrm{s}$ loading

\section{Conclusion}

The rate effect in cyclic loads to an instrumented pile model embedded in dry homogeneous sand is investigated experimentally under $1 \mathrm{~g}$ condition. Wide range of velocities are applied with various displacement amplitude at the pilehead fixed in rotational direction. The loading rate effect is analysed on force-displacement relationship and bending moment, deflection and soil reaction profile over the length of the pile. Based on the results, itis concluded that the lateral bearing capacity of the pile subjected to cyclic loading significantly exhibits rate dependent characteristics. The rate dependent behaviour of bearing capacity can be approximated with a linear function of logarithmic of loading rate. However, the failure pattern of the soil near the pile is considered as a consistent behaviour. These findings provide valuable understanding of the laterally loaded pile under cyclic loading, which may help engineers to evaluate performance of the pile foundation more precisely. 


\section{Acknowledgements}

This work was supported by KAKENHI Grant-in-Aid for Scientific Research (B) JP18H01517 from Japan Society for the Promotion of Science (JSPS).

\section{References}

[1] S. Banerjee, S. H. Goh, and F. H. O. U. Lee, "Response of Soft Clay Strata and Clay-Pile-Raft Systems to Seismic Shaking," J. Earthq. Tsunami, vol. 01, no. 03, pp. 233-255, 2007.

[2] R. W. Boulanger, C. J. Curras, B. L. Kutter, D. W. Wilson, and A. Abghari, "Seismic Soil-Pile-Structure Interaction Experiments and Analyses," J. Geotech. Geoenvironmental Eng., vol. 125, no. 9, pp. 750-759, Sep. 1999.

[3] B. Manna and D. K. Baidya, "Nonlinear Dynamic Response of Piles under Horizontal Excitation," J. Geotech. Geoenvironmental Eng., vol. 136, no. 12, pp. 1600-1609, Dec. 2010.

[4] C. Zhang, D. White, and M. Randolph, "Centrifuge Modeling of the Cyclic Lateral Response of a Rigid Pile in Soft Clay," J. Geotech. Geoenvironmental Eng., vol. 137, no. 7, pp. 717-729, Jul. 2011.

[5] T. Kokusho and T. Iwatate, "Scaled Model Tests and Numerical Analyses on Nonlinear Dynamic Response of Soft Grounds," Proc. Japan Soc. Civ. Eng., vol. 1979, no. 285, pp. 57-67, May 1979.

[6] A. E. Haiderali and G. Madabhushi, "Evaluation of Curve Fitting Techniques in Deriving p-y Curves for Laterally Loaded Piles," Geotech. Geol. Eng., vol. 34, no. 5, pp. 1453-1473, Oct. 2016.

[7] T. Zhao and Y. Wang, "Interpretation of pile lateral response from deflection measurement data: A compressive sampling-based method," Soils Found., vol. 58, no. 4, pp. 957-971, Aug. 2018.

[8] K. Madhusudan Reddy and R. Ayothiraman, "Experimental Studies on Behavior of Single Pile under Combined Uplift and Lateral Loading," J. Geotech. Geoenvironmental Eng., vol. 141, no. 7, p. 04015030, Jul. 2015.

[9] G. Poulos, Harry, "Single Pile Response to Cyclic Lateral Load," J. Geotech. Eng. Div., vol. 108, no. 3, pp. 355-375, 1982.

[10] L. G. Kong and L. Zhang, "Rate-controlled lateral-load pile tests using a robotic manipulator in centrifuge," Geotech. Test. J., vol. 30, no. 3, pp. 192-201, Jan. 2007. 